\title{
Idiopathic Unilateral Isolated Hypoglossal Nerve Palsy : A Case Report
}

\section{Nikhil Marwah, Archna Agnihotri, Mahesh Goel}

\section{ABSTRACT}

A Idiopathic isolated hypoglossal nerve palsy is an extremely rare condition. Presented here is a case report of self limiting IHNP on the basis of clinical finding and criteria of exclusion as all the investigations including ultrasound were negative. The patient is on speech therapy and is being actively rehabilitated.

\section{Contact Author}

Dr. Nikhil Marwah

E-mail : dr_nikhilmarwah@rediffmail.com

\section{Key Words:}

$\mathrm{I}$ diopathic isolated hypoglossal nerve palsy (IHNP) has been documented by several authors. Except for paresis of the facial nerve, mononeuropathies in childhood are very rare. Isolated hypoglossal nerve palsy is a rare condition and may be due to vaccination, aneurysms, trauma, dislocation of vertebrae, intracranial tumor or infectious processes such as infectious mononucleosis(1). In the literature, there are a few reports about isolated, unilateral hypoglossal nerve palsy (2 5 ) and even fewer reported cases of self limiting IHNP (6).

\section{Case Report}

A 6 year old child was referred to the Department of Pedodontics and Preventive Dentistry, Government Dental College, Rohtak to rule out any dental cause for speech defects present in the child. He had experienced difficulty in speaking and reading aloud for long periods. He also had difficulty in swallowing. There was no history of trauma, viral infection, stroke or surgery. Skin was normal in appearance. He did not have lymphadenopathy or organomegaly. The left side of the tongue was atrophic and deviated to the left side on protrusion (Fig. 1) and fasciculations were noted on the deviated side. OPG revealed no significant findings and all dental causes were non-significant. He was referred to the Department of Neurology for various investigations and the investigative approach followed was based on as recommendations by Ho, Frady and Crean (1). A complete blood cell count, peripheral blood smear, urinalysis findings, biochemical investigations, Thyroid function test, slide test for infectious mononucleosis (monospot), herpes simplex virus $\operatorname{IgM}$ and $\mathrm{G}$, anti cytomegalovirus (CMV), Epstein-Barr virus (EBV), ESR, serum electrophoresis, auto-antibodies all were negative. Chest Xray was normal, with no sign of sarcoidosis. CT and MRI were unremarkable. Cranial and cervical magnetic resonance imaging (MRI) did not reveal any brain tumor or ischemic lesion. On the MRI, hypoglossal nerve and hypoglossal foramen were normal. His neurological examination was completely normal except for tongue deviation, atrophy and fasciculations. Ultrasound of the tongue revealed hemiatrophy of the tongue, the muscle mass was greatly reduced with fatty displacement. Subjecting the tongue to M-mode Echomyography revealed

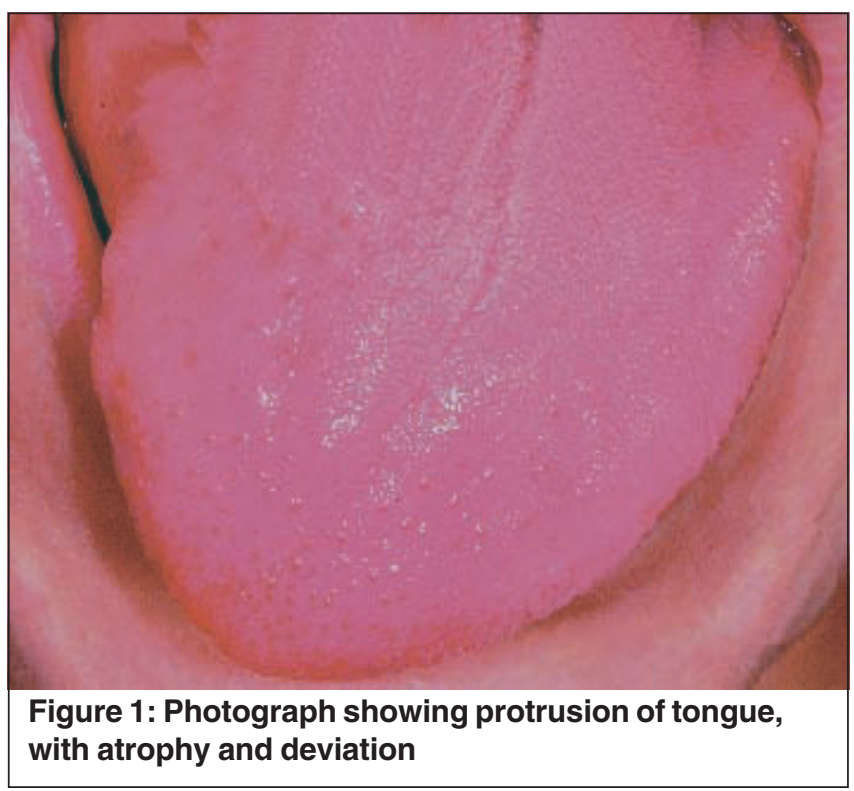


quiver in the wave pattern during the recording due to the affected side on protrusion and retrusion of the tongue. No other local structural defect was revealed during the ultrasound examination. He was then referred to ENT examination which failed to reveal any cause of tongue deviation.

History revealed that the patient was unable to speak properly since one year. Unilateral isolated hypoglossal nerve palsy suggested that the cause might be a local vasculitis lesion or a cerebro-vascular accident or any birth trauma. Normal vaccination schedule that was followed for the patient could have been the triggering factor. However, there was no evidence to support this provisional diagnosis. Speech and language therapy assessment was arranged for the patient. He was treated with multivitamins, and examined periodically every other week, there was no recovery even six months clinically as well as on Ultrasound, but the patient was more comfortable while speaking after speech therapy. The patient is now on regular follow up to check for progression and to rule out any possibility of demyelinating disease.

\section{Discussion}

Hypoglossal nerve motor composition is highly complex and not fully understood, with the nucleus consisting of four topographically distinct subnuclear columns(6). Peripheral lesions of the hypoglossal nerve are generally classified into four categories: extramedullary intracervical lesions, hypoglossal foramen lesions, extracranial lesions of the XII ${ }^{\text {th }}$ nerve at the base of the skull, and cervical hypoglossal nerve lesions (6). The possible causes of hypoglossal nerve palsy have been listed in Table 1. In our patient, investigations of the cervical base of the skull showed no abnormal findings. A

Table 1: Possible causes of isolated hypoglossal nerve palsy

\section{Possible causes}

- Metastatic disease at base of skull

- Medical causes eg sarcoidosis, autoimmune disease, vasculitis

- Arnold Chiari malformation

- Dural arteriovenous fistula of the transverse sinus

- Periostitis of hypoglossal canal

- Post-retropharyngeal infection

- Surgical procedure near neck

- Acute poliomyelitis

- Syringobulbia

- Thrombosis of median branches of vertebral artery

- Multiple sclerosis

- Carotid artery dissection/aneurysm

- Diabetes mellitus

- Lacunar infarct over the hypoglossal nerve nucleus

- Rare sequelae of central venous catheterisation6

- Head and neck trauma7 eg subluxation of odontoid process

- Fracture through the occipital condyle8

- Glomus tumour

- Meningioma

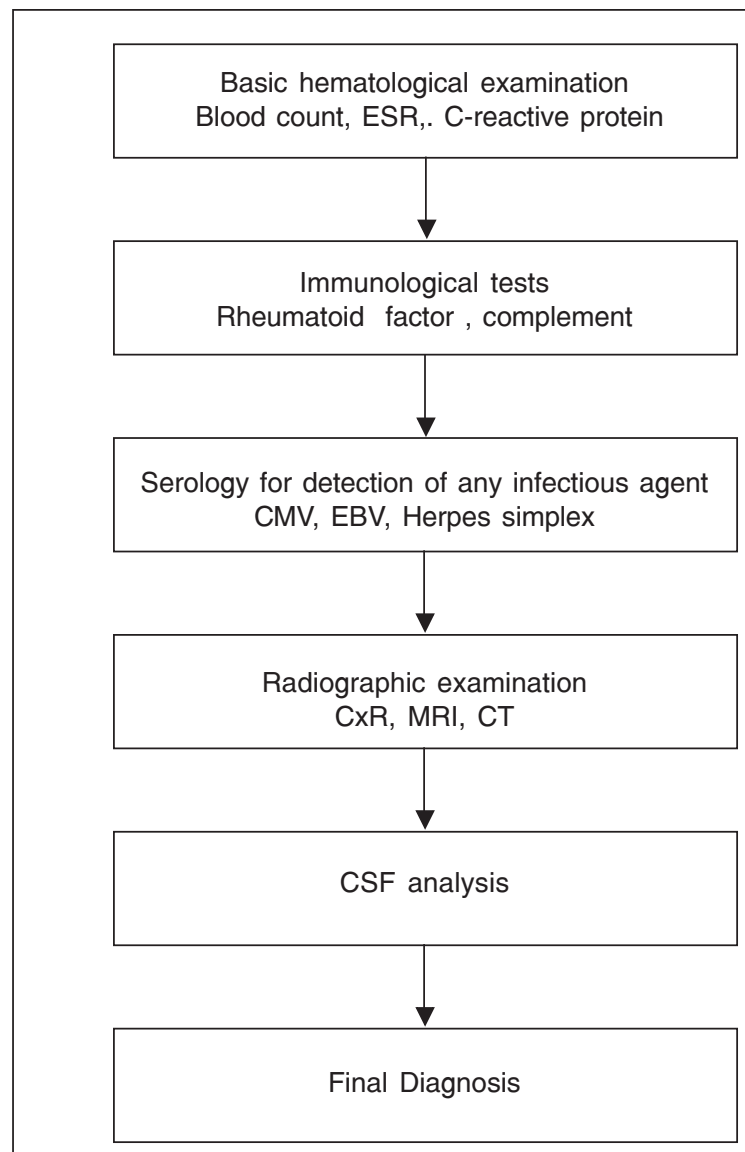

\section{Figure 2: Basic investigation table}

wide group of possible diagnosis may reveal themselves after a number of investigations. One suggested pathway as recommended by HO, Frady and Crean was followed in this case, and serves as a possible investigative approach when faced with such diagnostic problem (Fig 2). Thus with the diagnosis of exclusion the clinician can make a true diagnosis of idiopathic IHNP. A patient with these symptoms must always be referred to the Department of Neurology or Oral maxillofacial surgery where investigations can be undertaken. In the present case the investigations as illustrated in Fig 2 was followed all the findings were negative except the tongue deviation, atrophy and fasiculations. Thus the diagnosis of idiopathic unilateral IHNP was made. The possibility of demyelinating diseases in such patients can't be ruled out so periodic MRI scan every 35 years are a just requirement.

\section{THE AUTHORS}

\section{Dr. Nikhil Marwah}

M.D.S

Reader

Deptt. Of Pedodontics \& Preventive Dentistry,

Mahatma Gandhi Dental College \& Hospital

Jaipur, Rajasthan

E-mail: dr_nikhilmarwah@ rediffmail.com 


\section{Dr. Archna Agnihotri}

M.D.S

Asst. Professor

Department of Pedodontics and Preventive Dentistry, Dr. H.S. Judge Institute of Dental Sciences \& Hospital Chandigarh

\section{Dr. Mahesh Goel}

M.D.S

Asst. Professor

Department of Oral \& Maxillofacial Surgery,

Govt. Dental College, Rohtak-124001,

Haryana, India.

\section{References}

1. Ho MSW, Fardy MJ, CREAN SJV. Persistent idiopathic hypoglossal nerve palsy. BDJ 2004;196 (4):205-07.

2. Aynaci FM, len $Y$, Boz C, Orhan F. Isolated hypoglossal nerve palsy in a child. Turk J Pediatr 2004;46:101-03.

3. Bagan-Sebastian JV, Milian-Masanet MA, Penarrocha-DiagoM. Persistent idiopathic unilateral hypoglossal nerve palsy. J Oral Maxillofac Surg 1998; 56:507-510.

4. Castling $\mathrm{B}$, Hicks $\mathrm{K}$. traumatic isolated unilateral hypoglossal nerve palsy-case report and review of literature. $\mathrm{Br} J$ Oral Maxillofac Surg 1995; 33:171-173.

5. Omura S, Nakajima Y, Kobayashi S, Ono S, Fujita K. Oral manifestations and differential diagnosis of isolated hypoglossal nerve palsy: report of two cases. Oral Surg, Oral Med, Oral Pathol, Oral Rdiol, Endod 1996;84(6):635-40.

6. Keane JR. Twelth nerve palsy: Analysis of 100 cases. Arch Neurol 1996;53:561-66. 